\title{
Interactive behaviors between mothers and their prematurely born infants in the face-to-face Still-Face Paradigm
}

\author{
Relações entre os comportamentos interativos maternos \\ e de bebês prematuros no contexto do Face-to-Face \\ Still-Face
}

\author{
Taís CHIODELLI' (iD) 0000-0002-8586-1111 \\ Olga Maria Piazentin Rolim RODRIGUES'1 (iD) 0000-0002-5332-256X \\ Veronica Aparecida PEREIRA ${ }^{2}$ (iD) 0000-0002-9051-7550 \\ Pedro LOPES DOS SANTOS 3 (ID) 0000-0002-0754-580X \\ Marina FUERTES ${ }^{4}$ (iD) 0000-0001-7061-5092
}

\begin{abstract}
The present study compared and correlated interactive behaviors of 15 mothers and their very preterm infants (gestational age: 28-32 weeks). Mothers and infants were observed in the experimental Face-to-Face Still-Face paradigm, consisting of three episodes: in the first and third episodes (play and reunion episodes), mother and infant interact freely; in the second (still-face episode), the mother maintains a still-face expression. The behaviors of the infants were allocated in
\end{abstract}

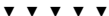

1 Universidade Estadual Paulista Júlio de Mesquita Filho, Faculdade de Ciências, Programa de Pós-Graduação em Psicologia do Desenvolvimento e Aprendizagem. Av. Engenheiro Luiz Edmundo Carrijo Coube, 14-01, Departamento de Psicologia, Vargem Limpa, 17033-360, Bauru, SP, Brasil. Correspondence to: O.M.P.R. RODRIGUES. E-mail: <olga.rolim@unesp.br>.

${ }^{2}$ Universidade Federal da Grande Dourados, Faculdade de Ciências Humanas, Programa de Pós-Graduação em Psicologia. Dourados, MS, Brasil.

${ }^{3}$ Universidade do Porto, Centro de Psicologia, Faculdade de Psicologia e de Ciências da Educação. Porto, Portugal.

${ }^{4}$ Instituto Politécnico de Lisboa, Escola Superior de Educação de Lisboa, Intervenção Precoce. Lisboa, Portugal. Support: Fundação de Amparo à Pesquisa do Estado de São Paulo (Process no 2014/10653-4).

Article based on the doctoral dissertation of T. CHIODELLI entitled "Temperamento e prematuridade: influências sobre a interação mãebebê". Universidade Estadual Paulista Júlio de Mesquita Filho, 2016.
}

$\checkmark \nabla \nabla$

How to cite this article

Chiodelli, T., Rodrigues, O. M. P. R., Pereira, V. A., Lopes dos Santos, P., \& Fuertes, M. (2020). Interactive behaviors between mothers and their prematurely born infants in the face-to-face Still-Face Paradigm. Estudos de Psicologia (Campinas), 37, e180164. http://dx.doi. org/10.1590/1982-0275202037e180164 
three categories: positive social orientation, negative social orientation and self-regulation. Maternal behaviors were classified into positive and negative social orientation. Intragroup comparisons indicated that maternal vocalizations were significantly higher in the play episode. Compared to other studies with preterm infants, babies in this study exhibit fewer interactive behaviors and more self-soothing behaviors in the still-face episode. In addition, in the reunion episode, values of the behaviors presented in the play episode were recovered. Correlations between intrusive maternal behaviors and noninteractive or negative-interaction behaviors of the infant suggest the relevance of providing intervention to promote maternal sensitivity.

Keywords: Infant, premature; Infant behavior; Mother-child relations.

\section{Resumo}

O presente estudo buscou comparar e descrever a correlação entre comportamentos interativos de quinze mães e seus bebês nascidos muito prematuros (idade gestacional: 28-32 semanas). As díades foram observadas com base no paradigma experimental do Face-to-Face Still-Face, composto por três episódios: nos Episódios 1 e 3 mãe e bebê interagem e, no Episódio 2, a mãe mantém-se inexpressiva. Os comportamentos dos bebês foram analisados conforme três categorias: orientação social positiva, orientação social negativa e autorregulação. Os comportamentos maternos foram classificados em orientação social positiva e negativa. Comparações intragrupo apontaram que as vocalizações maternas foram significativamente maiores no Episódio 1. Comparativamente a outros estudos com prematuros, os bebês deste estudo apresentaram menos comportamentos interativos e mais comportamentos de autoconforto no Episódio 2. No Episódio 3 os comportamentos interativos, tanto das mães quanto dos bebês, recuperaram as frequências apresentadas no Episódio 1. As correlações entre comportamentos maternos intrusivos e comportamentos não interativos ou de interação negativa com o bebê sugerem a relevância de se oferecerem intervenções para promover a sensibilidade materna.

Palavras-chave: Recém-nascido prematuro; Comportamento do lactente; Relações mãe-filho.

Child development and learning largely depend on the quality of the interactions experienced. The success of these interactions contributes to the mutual regulation of interactions (Gianino \& Tronick, 1988). In this process of mutual regulation, both partners (child and parent) contribute to engaging behavior, interactive errors, and reparation (Beeghly \& Tronick, 2011). During these interactions, parents' sensitivity to the infant's needs combined with child cooperation promote positive and reciprocal relationships (Beeghly, Fuertes, Liu, Delonis, \& Tronick, 2011).

A few decades ago, trying to evaluate the infants' regulation, Tronick, Als, Adamson, Wise, \& Brazelton (1978) proposed an Experimental Paradigm - Face-to-Face Still-Face (FFSF). The experimental paradigm consisted of an observation of the mother-infant interaction into three episodes. In the first episode (play episode), the mother was instructed to interact with her infant as she would normally do in her daily interactions. In the second episode, the mother would sit facing her infant, maintaining eye contact, but with a neutral expression, failing to respond to the behaviors presented by her infant. This episode was named still-face. In the third episode (reunion episode), the mother resumed interaction with her infant, following the guidelines of the first episode. During the Still-Face, infant behavior changed considerably, diminishing the amount of smiles and eye contact and increasing negative behaviors and emotion self-regulation.

From a behavioral perspective, in the second episode there was a change in the infant's positive states (Adamson \& Frick, 2003; Field, Vega-Lahr, Scafidi, \& Goldstein, 1986; Mesman, ljzendoorn, \& BakermansKranenburg, 2009), reflected by: increased crying and negative verbalizations, arching or frowning; decreased eye contact or gaze deviation; reduced number of smiles and of positive facial expressions; increased muscle tension and increased reactive motor activity, among other behaviors.

There is also evidence in the literature of a carry-over effect, that is, the infant exhibits less positive and more negative responses at the beginning of the reunion episode (resumption of interaction with the mother), when compared to the frequency of these behaviors in the play episode, recovering in part from 
the still-face episode (Mesman et al., 2009). Still, in the comparisons made between the behaviors of infants in the play and reunion episodes, there is a significant decrease in positive affect and a significant increase in negative affect; there are no significant variations in the behaviors of gazing at mother and neutral affect (Mesman et al., 2009).

Regarding the changes observed in the infant's behavior in the resumption of interaction with the mother, the meta-analysis conducted by Mesman et al. (2009) assessed that the infants significantly increased gazing at their mother and display of positive affection (e.g., positive vocalizations, smiles); they significantly reduced neutral affect, and continued to display negative affect behaviors such as crying and protesting. The authors argue that full recovery occurs a short time after the interaction has been reestablished.

An infant who responds intensely to changes in the environment may experiences difficulties to resume interaction with his/her mother and maintain negative interactive behaviors such as protest vocalizations, crying, and excessive agitation (Gunning, Halligan, \& Murray, 2013). These infants are less available to their mothers and may struggle to reengage in normal interaction while challenging their caregivers.

Not only does the infant's behavior change over the course of FFSF episodes. Mothers need to use more interaction repair strategies, including increased affective, infant-focused responses etc. (Hsu \& Jeng, 2013; Mesman et al., 2009).

Relationships between maternal and infant behavior in FFSF episodes were also observed and investigated. In the literature review and meta-analysis conducted by Mesman et al. (2009), maternal sensitivity or positive mother behaviors were associated with higher positive affect responses of the infant and lower negative affect responses in the still-face and reunion episodes.

Lowe et al. (2012) investigated associations between maternal interaction style and infants' affect and found that infants of mothers who displayed more contingent responses during FFSF had more positive affect in the play and reunion episodes and more changes in negative affect between play and still-face episodes. Other relationships were observed, such as reduced positive affect display in the play and reunion episodes and less stress responses as mothers showed more behaviors to attract the infant's attention. Other studies have found relationships between maternal sensitivity and affective and behavioral responses of infants during the first year of life (Braungart-Rieker et al., 2014; Gunning et al., 2013).

The study of emotion self-regulation with preterm infants has been performed by several authors (Montirosso et al., 2016; Muller-Nix et al., 2004). Fuertes, Lopes dos Santos, Beegly, and Tronick (2009) conducted a study with 57 preterm infants observed at three months of life in the FFSF, distinguishing three groups according to the emotion regulation patterns demonstrated over the three episodes: Group 1 with socially positive pattern, Group 2 with socially negative pattern, and Group 3 which pattern of state self-regulation was characterized by self-comforting behavior compared to the other two groups. However, self-comforting behavior decreased substantially in the maternal still-face episode and was very high in the other two episodes. Considering the outcome of these studies and other investigations conducted with Portuguese samples, it was observed that the state self-regulation pattern is significantly more frequent in preterm infants compared to term infants (Fuertes et al., 2014; Seixas, Barbosa, \& Fuertes, 2017). The results of this study are original in finding three self-regulation patterns. To this end, the authors contribute by counting the results of the three episodes.

As far as we know, studies with very preterm infants (born between 28 to 32 gestational weeks) are scarce. Studies indicate more self-comforting behaviors and fewer positive responses, especially in the reunion episode (Jean \& Stack, 2012). Yaari et al. (2018) investigated three groups of infants (extreme preterm, very preterm and full term) in the context of FFSF. Preterm infants displayed significantly less positive affect on interaction than term infants. Extreme preterm infants showed lower frequencies of self-comforting behaviors throughout the episodes while very preterm infants more frequently displayed these behaviors in the absence 
of interaction with the caregiver (still-face episode), indicating more developed emotional regulation skills compared to extreme preterm infants. However, differing from what is observed in term infants, who did not show variations in these behaviors during the FFSF episodes, the authors suggest that Full-Term infants may show more efficient emotion-regulation strategies. The present study aims to observe preterm infants throughout the three episodes and to verify their activity level from the first to the second and from the second to the third episode.

It is considered that very preterm infants may be less prepared than full term infants to interpret and respond to environmental stimuli and present self-regulatory difficulties during FFSF (Hsu \& Jeng, 2008; Yaari et al., 2018). In this connection, the FFSF enables the observation of the maternal and infant interactive behaviors in a structured situation and the observation of the infants' responses to a stressful event (absence of interaction in still-face episode), creating an opportunity for the infants to use the emotional self-regulation skills that will help them maintain their positive state. Behaviors such as putting the hands in their mouth, gaze aversion, closing their eyes, being distracted by objects, touching parts of their body, are self-regulating responses that can be part of the infant's repertoire that should be observed during the procedure. In addition, although FFSF is a worldwide used procedure to assess infant emotion self-regulation skills, studies with Brazilian samples are scarce (Chiodelli, 2016; Ribeiro, 2017). Therefore, in view of the intent to expand studies on mother-infant interaction in the framework of the FFSF paradigm, the present study seeks to: (a) describe and compare the behaviors of mothers of very premature infants in the FFSF play and reunion episodes, (b) describe and compare the behaviors of very preterm infants in the three episodes of FFSF and, (c) describe the correlation between maternal behavior and very preterm infants.

\section{Method}

\section{Participants}

The study sample consisted of fifteen infants born between 28 and 32 gestational weeks. $(M=$ 30.1; $S D=1.68$ ) and their mothers. The infants, seven female and eight male, were recruited from an early intervention program at a rehabilitation facility and at a follow-up outpatient clinic for very low birth weight infants from a public maternity ward. Both institutions were located in a city in the interior of the State of São Paulo. The inclusion criteria were mothers with no clinical medical history and infants without disabilities or comorbidities.

The infants had a mean chronological age of 5.04 months ( $S D=0.68$; Minimum $=5$ months; Maximum $=6.22$ months). Using gestational corrected age, premature infants were between three and four months of corrected age. The infants birth weight ranged from 1,075 to 2,490 grams ( $M=1500.6$; $S D=424.7)$; ten of these children (66.6\%) were born by caesarean section and the remaining five (33.3\%) of vaginal delivery. After birth, infants were hospitalized for an average 27.1 days (SD = 10.0; Minimum = 7 days; Maximum $=45$ days). The average maternal age was 29.2 years $(S D=5.41$; Minimum = 22; Maximum = 38); nine mothers $(60.0 \%)$ had completed high school, four mothers $(26.6 \%)$ completed elementary school and one mother (6.6\%) completed higher education. Nine mothers (60.0\%) had stable jobs and six mothers (40.0\%) were not in the labor market at the time of collection. Thirteen mothers (86.6\%) lived with their children and their partner, one mother (6.6\%) lived with her child and the family of origin and one mother (6.6\%) lived alone with her children. Nine mothers $(60.0 \%)$ had two or more children and six mothers $(40.0 \%)$ were primiparous. Ten mothers (66.6\%) had not planned pregnancy and five mothers (33.3\%) reported having planned pregnancy. The fifteen mothers (100\%) were followed up during the prenatal period and the average number of visits to the doctor's office was $3.2(S D=6.0 ;$ Minimum $=1$; Maximum $=10)$. 


\section{Instruments}

To collect family demographics an interview was conducted with direct and open questions. The regarding pregnancy, childbirth and postnatal period. The interaction between mother and infant was videotaped during the FFSF paradigm procedure (Tronick et al., 1978). For simultaneous video recording, two digital camcorders, two tripods and chair adapted with reclining backrest and adjustable height were used, enabling face-to-face interactions between the dyads. the videos were paired using the Sony Vegas Pro 13.2 software.

The infant's interactive behaviors were recorded at five-second intervals and were coded using the Still-Face Expression of Children Behavior Coding and Analysis System (Fuertes et al., 2009; Fuertes, Beeghly, Lopes dos Santos, \& Tronick, 2011). The listed infant and maternal behaviors were organized into categories: Positive Social Orientation (looking at the mother's face, looking at the mother's body, smiling, reaching the mother, positive/neutral vocalizations and motor agitation), Negative Social Orientation (negative facial expressions, excessive motor activity, vocal protests, escaping from the mother, arching the body, pushing away from the mother and crying) and Self-regulation (mother's gaze aversion, closing the eyes, taking hands to mouth, oral objects, handling objects, avoiding mother and squeezing hands against each other).

As for maternal interactive behaviors, an adaptation of the analysis proposed by Varão (2012) was implemented. Maternal behaviors were categorized as: Positive Social Orientation (approaching the infant's face, establishing physical contact with the infant, vocalizing directly to the infant, singing to the infant, tickling the infant, kissing the infant, playing with the infant and responding to the infant's contact initiatives) and Negative Social Orientation (moving away from the infant, avoiding playing with the infant, avoiding eye contact or body contact with the infant, making negative infant attributions or negative descriptions of their states, intrusive oral behavior with infant like sucking their hands, physically restriction of infant's movements and proximity with the infant's face (infant face less than $30 \mathrm{~cm}$ - intrusiveness).

\section{Data collection}

Infants eligible for the study were identified from the medical records of the two institutions. Mothers were contacted on pediatric visits. The study aims and procedures were explained to mothers by a female research assistant who invited parents to take part in this investigation. Mothers agreeing on their participation signed the Informed Consent Form. Visit and schedule time were decided according the best convenient time for mothers and infants. During the session, the instruments were applied according to each institution ethical procedures in an individual care room prepared to ensure mothers' privacy. They were then videotaped interacting with their infants according to the FFSF procedure (Tronick et al., 1978).

Filming lasted up to nine minutes, three for each episode. The infant remained seated in an ageappropriate reclining seat and the mother sat opposite her infant so that they could be face to face. During the play episode the mother was instructed to interact with her infant as she was used to, without using toys or other infant accessories such as a pacifier. In the still-face episode the mother was told to keep only eye contact with the infant. In this episode, manifestation of discomfort, identified by crying during 15 consecutive seconds, led to the interruption of the experiment. In the reunion episode the interaction between the dyad was resumed, with instructions similar to the play episode.

\section{Data analysis}

Interactive dyadic behaviors were recorded at five-second intervals, with 108 intervals (36 intervals from each FFSF episode) of infant behavior and 72 mother intervals (play and reunion episodes). The frequencies 
of the behaviors were weighted by the number of analyzed intervals when the filming had to be interrupted due to the infant's crying. The calculation used was: number of observed behaviors divided by the number of recorded intervals, multiplied by the number of expected intervals (36 per episode).

Twelve videos ( $30 \%$ of the sample) were selected to calculate the agreement between two independent trained coders. Intraclass correlations were performed, which showed coefficients higher than 0.8 for all categories analyzed, a value considered in the literature as excellent (Cicchetti, 1994).

For the statistical analysis, nonparametric tests were used due to the absence of normal distribution verified by the Shapiro-Wilk Test. The Wilcoxon statistical test was used for intragroup comparisons and Spearman for correlations. The value of rho indicates the strength of the correlation and the classification adopted refers to that presented by Pestana and Gageiro (2014), as follows: < 0.2 - very weak; 0.2 to 0.4 - weak; 0.41 to 0.7 - moderate; 0.71 to 0.9 - high; above 0.9 - very high; 1.0 - Perfect. The analyses were conducted using the IBM ${ }^{\circledR}$ SPSS ${ }^{\circledR}$ Statistics (version 2.0).

Comparisons of maternal and infant behaviors during the episodes tested the following hypotheses: maternal responsiveness - mothers maintain the behavioral pattern, with no significant differences between the play and reunion episodes; infants display the still-face effect (increased Negative Social Orientation and Self-Regulation behaviors in the still-face episode and recovery in the reunion episode). Correlations were conducted to verify the hypotheses: (1) positive correlation between Positive Social Orientation infants' behavior and Positive Social Orientation behaviors of the mothers, confirming the relationships identified by some studies, (2) positive correlation between behaviors of Negative Social Orientation of the infants and Self-Regulation and Negative Social Orientation maternal behaviors, in both the play and reunion episodes.

\section{Ethical Considerations}

This study is part of the project "Maternal and infant variables: correlation between interaction and child development", approved by the Ethics Committee of the Faculty of Sciences of Universidade Estadual Paulista-Bauru (Case $n^{\circ} 11187 / 46 / 01 / 2012$ ). Its was also authorized by the Ethics Committee of SORRI-Bauru and Maternidade Santa Isabel.

\section{Results}

Maternal and infant interactive behaviors were described and compared in FFSF episodes. For maternal behaviors we only considered the play and reunion episodes, since in the still-face episode the mother was instructed to remain unresponsive and only to maintain eye contact. Regarding the analyses conducted on the infants' behaviors, the display in the three episodes of the FFSF was considered.

Table 1 presents the findings regarding the maternal interactive behaviors. We only found significant differences in maternal behaviors between the play and reunion episodes regarding vocalizing directly to the infant. In fact, a decrease of vocalizations was observed in the reunion episode.

Regarding comparisons between the infants' behaviors during the FFSF episodes, it was observed that between the play and still-face episodes, infants decreased looking at their mothers' body $(p=0.001)$ and displayed fewer smiles $(p=0.012)$; they reduced attempts to reach their mother $(p=0.011)$, displayed less neutral or positive vocalizations $(p=0.012$ ) and the total Positive Social Orientation was lower in the still-face episodes $(p=0.002)$. Considering the negative interactive behaviors, the infants significantly increased the occurrence of vocal protests $(p=0.009)$, excessive motor activity $(p=0.003)$ and the total Negative Social 
Intragroup comparisons of maternal behaviors in FFSF play and reunion episodes

\begin{tabular}{|c|c|c|c|c|c|c|c|c|c|}
\hline \multirow{2}{*}{ Maternal interactive behaviors } & \multicolumn{4}{|c|}{ Play episode } & \multicolumn{4}{|c|}{ Reunion episode } & \multirow{2}{*}{$\begin{array}{l}\mathrm{PxR} \\
p^{*} \\
\end{array}$} \\
\hline & $M$ & $(S D)$ & Mdn & (Mín-Max) & $M$ & $(S D)$ & $M d n$ & (Mín-Max) & \\
\hline \multicolumn{10}{|l|}{ PSO } \\
\hline Approaching the infant's face & 12 & $(15.0)$ & 10 & $(0-36)$ & 11 & $(12.4)$ & 4 & $(0-35)$ & 0.169 \\
\hline Body contact with the infant & 29 & $(10.4)$ & 34 & $(5-36)$ & 30 & (8.4) & 34 & $(17-36)$ & 0.245 \\
\hline Vocalizing directly to the infant & 36 & $(8.4)$ & 37 & $(3-42)$ & 33 & (7.7) & 36 & $(8-40)$ & 0.027 \\
\hline Singing to the infant & 1 & (4.5) & 0 & $(0-8)$ & 3 & (6.0) & 0 & $(0-16)$ & 0.207 \\
\hline Tickling the infant & 2 & (2.5) & 0 & $(0-9)$ & 2 & (3.2) & 1 & $(0-11)$ & 0.725 \\
\hline Kissing the infant & 1 & $(2.2)$ & 0 & $(0-9)$ & 1 & (2.3) & 0 & $(0-8)$ & 0.798 \\
\hline Play with the infant & 1 & $(1.6)$ & 0 & $(0-6)$ & 1 & $(2.1)$ & 0 & $(0-7)$ & 0.607 \\
\hline $\begin{array}{l}\text { Responding to the infant's } \\
\text { contact initiatives }\end{array}$ & 3 & (3.2) & 2 & $(0-5)$ & 3 & (3.8) & 2 & $(0-11)$ & 0.972 \\
\hline Total PSO & 85 & $(23.1)$ & 83 & $(40-125)$ & 85 & $(25.1)$ & 85 & $(44-116)$ & 0.944 \\
\hline \multicolumn{10}{|l|}{ NSO } \\
\hline Moving away from the infant & 1 & (1.1) & 1 & $(0-4)$ & 2 & (2.1) & 1 & $(0-7)$ & 0.129 \\
\hline Avoiding play with the infant & 0 & (0.9) & 0 & $(0-4)$ & 0 & $(0.4)$ & 0 & $(0-2)$ & 0.593 \\
\hline $\begin{array}{l}\text { Avoiding eye or body contact } \\
\text { with the infant }\end{array}$ & 1 & $(1.7)$ & 0 & $(0-5)$ & 1 & $(1.3)$ & 1 & $(0-4)$ & 1.000 \\
\hline $\begin{array}{l}\text { Making negative infant } \\
\text { atrributions or descriptions of } \\
\text { their states }\end{array}$ & 4 & (5.6) & 1 & $(0-11)$ & 3 & (2.9) & 2 & $(0-11)$ & 0.929 \\
\hline Sucking the infant's hands & 0 & $(0.2)$ & 0 & $(0-1)$ & 0 & $(1.2)$ & 0 & $(0-5)$ & 0.102 \\
\hline Proximity with the infant's face & 2 & $(8.0)$ & 0 & $(0-2)$ & 2 & (4.6) & 0 & $(0-16)$ & 0.465 \\
\hline $\begin{array}{l}\text { Physically restrict of infant's } \\
\text { movements }\end{array}$ & 11 & $(14.2)$ & 3 & $(0-34)$ & 15 & $(12.7)$ & 14 & $(0-36)$ & 0.293 \\
\hline Total NSO & 20 & $(17.9)$ & 14 & $(1-45)$ & 23 & $(14.5)$ & 22 & $(4-49)$ & 0.293 \\
\hline
\end{tabular}

Note: * $p$ value obtained by Wilcoxon test. M: Mean; SD: Standard Deviation; Mdn: Median; Max: Maximum; Mín: Minimum; PSO: Positive Social Orientation; NSO: Negative Social Orientation; P: Play episode; R: Reunion episode.

Orientation $(p=0.016)$. Among non-interactive behaviors, there was a significant increase in the behavior of mother's gaze aversion ( $p=0.038)$, handling objects $(p=0.049)$ and total Self-Regulation $(p=0.010)$ (Table 2) during the still-face episode.

After the resumption of interaction by the mother, comparing the still-face and reunion episodes, the infants significantly increased the total behaviors of the Positive Social Orientation class $(p=0.004)$, specifically the smiles $(p=0.008)$ and the attempts to reach the adult $(p=0.034)$. Among negative interactive behaviors, there was also a reduction in motor reactivity $(p=0.008)$ and an increase in pushing away behavior $(p=$ $0.026)$ and, in non-interactive behaviors, a decrease in the total Self-Regulatory behaviors $(p=0.005)$ and handling objects $(p=0.013)$.

Comparing the infant's interactive behaviors before and after exposure to the still-face episode or maternal still-face, an increased looking at the mother's body $(p=0.001)$, motor agitation $(p=0.035)$ and a decrease in neutral or positive vocalizations $(p=0.045)$ occurred.

Table 3 presents the significant results of the correlation between maternal and infant behaviors obtained in the play and reunion episodes. In the play episode, most correlations were moderate $(r=0.4$ to 0.7 ) with only one robust and negative correlation between avoiding mother and maternal physical contact with the infant. Negative correlations were observed between infants' smiles and maternal physical contact, infant's protests and maternal closeness to the infant's face, pushing away from the mother and maternal vocalizations directly to the infant, avoiding mother and maternal physical contact, and infant's behavior of mother's gaze aversion and maternal behavior proximity to the infant's face (less than $30 \mathrm{~cm}$ ). Positive correlations were observed between the infant's behavior of body arching and maternal physical contact with the infant, infant's interactive behavior of taking hands to mouth and maternal interactive behavior of kissing the infant, infant's vocal protests and maternal negative vocalizations. 
Intragroup comparisons of infant behaviors in the three FFSF episodes

\begin{tabular}{|c|c|c|c|c|c|c|c|c|c|}
\hline \multirow{2}{*}{ Infant's interactive behaviors } & \multicolumn{2}{|c|}{ Play episode } & \multicolumn{2}{|c|}{ Still-face episode } & \multicolumn{2}{|c|}{ Reunion episode } & \multirow{2}{*}{$\begin{array}{l}\text { PxS } \\
p^{*} \\
\end{array}$} & \multirow{2}{*}{$\begin{array}{l}P \times R \\
P^{*} \\
\end{array}$} & \multirow{2}{*}{$\begin{array}{l}S \times R \\
p^{*} \\
\end{array}$} \\
\hline & Mdn & (Mín-Max) & Mdn & (Mín-Max) & Mdn & (Mín-Max) & & & \\
\hline \multicolumn{10}{|l|}{$\overline{P S O}$} \\
\hline Looking at the mother's face & 25 & $(2-35)$ & 17 & $(1-35)$ & 26 & $(1-36)$ & 0.132 & 0.450 & 0.442 \\
\hline Looking at the mother's body & 7 & $(1-27)$ & 0 & $(0-2)$ & 8 & $(0-21)$ & 0.001 & 0.001 & 0.528 \\
\hline Smiling & 6 & $(0-19)$ & 0 & $(0-14)$ & 3 & $(0-19)$ & 0.012 & 0.061 & 0.008 \\
\hline Reaching the mother & 1 & $(0-15)$ & 0 & $(0-1)$ & 0 & $(0-12)$ & 0.011 & 0.959 & 0.034 \\
\hline Positive or neutral vocalizations & 4 & $(0-22)$ & 1 & $(0-19)$ & 1 & $(0-23)$ & 0.012 & 0.045 & 0.208 \\
\hline Motor agitation & 0 & $(0-10)$ & 1 & $(0-21)$ & 0 & $(0-12)$ & 0.759 & 0.035 & 0.759 \\
\hline Total PSO & 51 & $(14-85)$ & 23 & $(5-74)$ & 42 & $(21-85)$ & 0.002 & 0.346 & 0.004 \\
\hline \multicolumn{10}{|l|}{ NSO } \\
\hline Negative facial expression & 2 & $(0-20)$ & 5 & $(0-18)$ & 6 & $(0-28)$ & 0.266 & 0.051 & 0.495 \\
\hline Vocal protests & 1 & $(0-16)$ & 3 & $(0-33)$ & 6 & $(0-11)$ & 0.009 & 0.574 & 0.080 \\
\hline Escaping from the mother & 0 & $(0-1)$ & 0 & $(0-3)$ & 0 & $(0-2)$ & 0.480 & 1.000 & 0.127 \\
\hline Arching the body & 0 & $(0-4)$ & 1 & $(0-18)$ & 0 & $(0-2)$ & 0.127 & 0.595 & 0.061 \\
\hline Pushing away from the mother & 0 & $(0-6)$ & 0 & $(0-3)$ & 0 & $(0-7)$ & 0.059 & 0.201 & 0.026 \\
\hline Crying & 0 & $(0-8)$ & 0 & $(0-4)$ & 0 & $(0-17)$ & 0.916 & 0.128 & 0.068 \\
\hline Excessive motor activity & 1 & $(0-12)$ & 7 & $(0-33)$ & 0 & $(0-11)$ & 0.003 & 0.836 & 0.008 \\
\hline Total NSO & 11 & $(0-57)$ & 31 & $(3-87)$ & 22 & $(5-66)$ & 0.016 & 0.061 & 0.523 \\
\hline \multicolumn{10}{|l|}{$\overline{S R}$} \\
\hline Mother's gaze aversion & 11 & $(0-29)$ & 19 & $(0-35)$ & 11 & $(1-32)$ & 0.038 & 0.887 & 0.050 \\
\hline Closing the eyes & 0 & $(0-1)$ & 0 & $(0-1)$ & 0 & $(0-5)$ & 0.564 & 0.285 & 0.197 \\
\hline Taking hand to mouth & 0 & $(0-14)$ & 1 & $(0-34)$ & 1 & $(0-13)$ & 0.221 & 0.624 & 0.050 \\
\hline Oral objects & 0 & $(0-0)$ & 0 & $(0-8)$ & 0 & $(0-2)$ & 0.180 & 0.157 & 0.414 \\
\hline Avoiding mother & 0 & $(0-17)$ & 0 & $(0-7)$ & 0 & $(0-5)$ & 0.497 & 0.248 & 0.227 \\
\hline $\begin{array}{l}\text { Squeezing hands against each } \\
\text { other }\end{array}$ & 0 & $(0-3)$ & 0 & $(0-20)$ & 0 & $(0-3)$ & 0.127 & 0.783 & 0.058 \\
\hline Handling objects & 1 & $(0-22)$ & 9 & $(0-35)$ & 0 & $(0-22)$ & 0.049 & 0.683 & 0.013 \\
\hline Total SR & 19 & $(0-45)$ & 43 & $(0-81)$ & 19 & $(2-42)$ & 0.010 & 0.220 & 0.005 \\
\hline
\end{tabular}

Note: ${ }^{*} p$ value obtained by Wilcoxon test. SR: Self-regulation; Max: Maximum; Mdn: Median; Mín: Minimum; NSO: Negative Social Orientation; PSO: Positive Social Orientation; P: Play episode; R: Reunion episode; S: Still-face episode.

Also in the reunion episode most correlations were moderate, whereas two were positive and robust, namely infants cry and maternal responses to the infant's contact initiatives (rhô $=0.822$ ) and infant interactive behavior of escaping from the mother and maternal interactive behavior of avoiding play with the infant ( $r$ ô $=0.732$ ). The infant's behavior of looking at the mother's face is positively correlated with the maternal behavior of singing and the maternal interactive behavior of moving away from the infant. Infant smiling is negatively correlated with maternal physical contact with the infant and positively correlated with the maternal behaviors of singing to the infant and moving away from the infant. A negative correlation was observed between infant positive or neutral vocalizations and maternal behavior of avoiding eye contact or body contact with the infant. The infant's negative facial expression correlated positively with maternal responses to the infant's initiatives. Infant's behavior of escaping from the mothers was positively correlated with maternal tickling the infant and maternal behavior of avoiding play with the infant. Infant's behavior of arching the body negatively correlated with maternal interactive behavior of playing with the infant and positively correlated with maternal behaviors of responding to the infant's initiatives. Another positive correlation was observed between infant crying and maternal responses to the infant's contact initiatives. The infant's behavior of excessive motor activity correlated negatively with maternal physical restraint of infant's movements. Regarding the infant's self-regulating behaviors, closing the eyes positively correlated with the maternal behaviors of singing to the infant, sucking the infant's hands and physically restraining the infant's movements. Infant's behavior of taking hands to mouth correlated negatively with maternal physical contact with the infant, and finally the infant's behavior of oral objects correlated positively with maternal

8 tickling of the infant. 
Table 3

Correlations between maternal and infant behaviors in play and reunion episodes

\begin{tabular}{|c|c|c|}
\hline \multicolumn{3}{|c|}{ Play episode } \\
\hline$\underline{\text { V1 (infant) }}$ & V2 (maternal) & Rô \\
\hline Smiling (PSO) & Establishing physical contact with the infant (PSO) & $-0.522^{*}$ \\
\hline \multirow[t]{2}{*}{ Vocal protests (NSO) } & Proximity with the infant's face (NSO) & $-0.640 *$ \\
\hline & Making negative infant attributions or negative descriptions of their states (NSO) & $0.644 * *$ \\
\hline Arching the body (NSO) & Establishing physical contact with the infant (PSO) & $0.562^{*}$ \\
\hline Pushing away from the mother (NSO) & Vocalizing directly to the infant (PSO) & $-0.527 *$ \\
\hline Look away (SR) & Proximity with the infant's face (NSO) & $-0.590 *$ \\
\hline Put the hand in the mouth (SR) & Kissing the infant (PSO) & $0.557^{*}$ \\
\hline Avoiding mother (SR) & Establishing physical contact with the infant (PSO) & $-0.795 * *$ \\
\hline \multicolumn{3}{|l|}{ Reunion episode } \\
\hline \multirow[t]{2}{*}{ Looking at mother's face (PSO) } & Singing to the infant (PSO) & $0.546^{*}$ \\
\hline & Moving away from the infant (NSO) & $0.542^{*}$ \\
\hline \multirow[t]{3}{*}{ Smiling (PSO) } & Establishing physical contact with the infant (PSO) & $-0.525^{*}$ \\
\hline & Singing to the infant (PSO) & $0.664 * *$ \\
\hline & Moving away from the infant (NSO) & $0.546^{*}$ \\
\hline Positive or neutral vocalizations (PSO) & Avoiding eye contact or body contact with the infant (NSO) & $-0.585^{*}$ \\
\hline Negative facial expression (NSO) & Responding to the infant's contact initiatives (PSO) & $0.595^{*}$ \\
\hline \multirow[t]{2}{*}{ Escaping from the mother (NSO) } & Tickling the infant (PSO) & $0.618^{*}$ \\
\hline & Avoiding play with the infant (NSO) & $0.732 *$ \\
\hline \multirow[t]{2}{*}{ Arching the body (NSO) } & Play with the infant (PSO) & $-0.549 *$ \\
\hline & Responding to the infant's contact initiatives (PSO) & $0.537 *$ \\
\hline Crying (NSO) & Responding to the infant's contact initiatives (PSO) & $0.822 * *$ \\
\hline Excessive motor activity (NSO) & Physically restrict of infant's movements (NSO) & $-0.674 * *$ \\
\hline \multirow[t]{3}{*}{ Closing the eyes (SR) } & Singing to the infant (PSO) & $0.593 *$ \\
\hline & Sucking the infant's hands (NSO) & $0.568^{*}$ \\
\hline & Physically restrict of infant's movements (NSO) & $0.553^{*}$ \\
\hline Taking hands to mouth (SR) & Establishing physical contact with the infant (PSO) & $-0.521 *$ \\
\hline Oral objects (SR) & Tickling the infant (PSO) & $0.623 *$ \\
\hline
\end{tabular}

Note: Values obtained by Spearman correlation $* p<0.005 ;{ }^{*} p<0.001$. SR: Self-regulation; NSO: Negative Social Orientation; PSO: Positive Social Orientation; Rô: Spearman's Correlation Coefficient; V1: infant variables (interactive behaviors); V2: maternal variables (interactive behaviors).

\section{Discussion}

In this study we performed intra-group comparisons and correlations between the behaviors of 15 mothers and their very preterm infants in FFSF episodes. Positive Social Orientation behaviors were the most frequent maternal behaviors in the FFSF play and reunion episodes. Mothers displayed more positive vocalizations, physical contact, and closeness to them, suggesting that these mothers were highly involved in the interaction with their infants. Montirosso, Borgatti, Trojan, Zanini, and Tronick (2010) also observed similar results; in their study mothers of premature infants showed positive and monitoring behaviors towards the infant similarly to mothers of full-term infants. However, such behaviors are expected since dyads were seated in a quite proximal position facing each other and the investigator requested mothers to interact with their infant as they usually do.

The hypothesis that mothers maintain a responsive behavioral pattern with no significant difference between FFSF episodes was partially confirmed, since when comparing the play and reunion episodes it was observed that mothers reduced the occurrence of positive vocalizations in the reunion episode, suggesting that still-face also has effects on maternal behavior (Hsu \& Jeng, 2013).

Infants showed variations in their behavior over the three FFSF episodes, discriminating changes in interaction. Between the play and still-face episodes there was the still-face effect, that is, a reduction in the display of Positive Social Orientation behaviors and an increase in Negative Social Orientation and Selfregulation behaviors. This result confirmed the study hypothesis and is consistent with the outcome of other investigations that also pointed to the still-face effect in samples of preterm infants (Fuertes et al., 2011; 
Montirosso et al., 2010). As observed by Yaari et al. (2018), the very preterm infants in this study had higher frequencies of Self-Regulatory behaviors in the still-face episode as compared to the other episodes.

After the mother resumed interaction with the infant, there were again variations in their behaviors, with the increase of Positive Social Orientation behaviors and decrease of Self-Regulation behaviors. The behaviors of the Negative Social Orientation category continued to be displayed, albeit at a lower frequency than in the still-face episode, but at a higher rate than in interaction with the mother before still-face. Montirosso et al. (2010) indicated a carry-over effect in both premature and term infants, pointing to a difficulty in resuming interaction with the mother, requiring more help for self-regulation after exposure to a stressful event. However, the infants in this study showed significantly more Positive Social Orientation behaviors in the reunion episode (looking at the mother and positive psychomotor agitation), interacting with the mother, suggesting that they were able to resume interaction with her. Montirosso et al. (2010) also observed that infants exhibited more gazes at the mother after the occurrence of still-face.

Mesman et al. (2009) argued that it may take a while for the infant to be able to regain interaction with the mother in the reunion episode. In their meta-analysis they observed a recovery effect for gazing-atmother behaviors and neutral affection; however, positive affect and negative affect take a little longer to be restored. The authors also pointed out that the short time of the procedure (ranging from two to three minutes) may be insufficient for full recovery from the interaction.

During the interaction, there were reciprocal and continuous exchanges between mother and infant, describing relationships between their responses and the consequences they produce for the other's behavior, creating conditions for the interaction to happen (Beeghly \& Tronick, 2011). Regarding the hypothesis that the infants would respond positively to the mothers' Positive Social Orientation behaviors and vice versa, it was observed that, in play episode, the infants looked at their mother's face and smiled at the maternal singing behavior, proving partially that hypothesis. Exposure of preterm infants to music can have positive effects on their ability to regulate (Garunkstiene, Buinauskiene, Uloziene, \& Markuniene, 2014), as well as strengthening the interaction between mother and infant (Palazzi, Meschini, \& Piccinini, 2019).

Unlike expected, relationships were observed between infants' Positive Social Orientation behaviors and mothers' Negative Social Orientation behaviors, such as infants looking and smiling at their mothers when their mothers moved away; this may indicate that infants develop strategies for resuming mother's attention. Negative relationships were also observed between dyad's Positive Social Orientation behaviors, such as reducing physical contact despite infants' smiles. Jean and Stack (2012) pointed out that maternal touch assumes different functions throughout the episodes of interaction with the infant in the framework of FFSF, contributing to the emotional regulation of the infant. The authors observed that, after the resumption of interaction with the infant, mothers more frequently displayed touches with the function of playing with and stimulating the infant, which would help infants to calm down and to engage again in the interaction. In the study by Mantis and Stack (2018), preterm infant-mothers dyads presented higher frequencies of touches with the function of attracting attention and guiding the other's exploratory touch when compared to full-term infants-mothers dyads. Considering the results of this study, it may be suggested that mothers used physical contact to attract their infants attention, calm them down and engage them again in the interaction, and once the interaction was re-established, physical contact diminished.

The hypothesis that infants would respond negatively to mothers' Negative Social Orientation behaviors was partially confirmed. In the play episode, when faced with infants' behaviors, such as protesting, mothers responded with negative vocalizations. However, in the reunion episode, mothers also significantly displayed Positive Social Orientation behaviors when facing infants' Negative Social Orientation behaviors, probably with the intention to soothe them, such as the infant's arching, trying to escape and crying that were followed by maternal behaviors of maintaining physical contact, tickling and responding to the infant's initiatives. 
These results may also suggest that mothers responded more to their infants contact initiatives when such initiatives involved negative behaviors, indicating the need to help them discriminate and respond contingently to other infant's responses, such as those in the Positive Social Orientation class. The development and offer of intervention programs for the mothers could promote the quality of bonding between them and their premature infants and increase maternal responsiveness (Borghini et al., 2014; Dibley, Rydin-Orwin, Stedmon, \& Dallos, 2016).

It was also observed that the infants showed negative or non-interactive behaviors in relation to maternal intrusive behaviors, such as taking the hands to their mouths, closing their eyes upon mothers' kissing, sucking and physically restricting behaviors. There is evidence that mothers of premature infants have more intrusive and directive behaviors in their interaction with their infants compared to mothers of full-term infants (Agostini, Neri, Dellabartola, Biasini, \& Monti, 2014; Loi et al., 2017). In this sense, identifying the roles that maternal behaviors play in interacting with their infant can contribute to interventions that help mothers identify these functions and develop an alternative repertoire.

The present study, by comparing interactive behaviors of very preterm infants - mothers in the three episodes of FFSF, made it possible to observe that the infants maintained positive interactive behaviors with their mothers in the play episode, managed to self-regulate in the still-face episode and resumed interaction at the same level in the reunion episode, differing from the results found by other studies suggesting greater difficulty for preterm infants to self-regulate (Hsu \& Jeng, 2008; Yaari et al., 2018). Correlations between maternal and infant interactive behaviors have been observed, and in some cases, such as the presence of intrusive behaviors and the relationship with noninteractive or interacting negative behaviors suggest that interventions with mothers could improve the relationship between the dyad, making mothers more sensitive to their infant's needs. Consequently, preventive approaches and humanized attention to the newborn, such as the Kangaroo Mother Method, interventions performed during the hospitalization of the infant and that accompany the transition from hospital to home can help support the infant's self-regulation from birth, favor the relationship between mother and child, and also act as facilitators of positive interaction routes (Beebe et al., 2018; Nayak et al., 2019; Vonderheid et al., 2016). The results obtained by the study are associated with a body of knowledge that contributes to the practices supported by empirical evidence with families of preterm infants, in order to benefit the mother-infant relationship and the infant's developmental processes. However, there are some limitations, such as the reduced number of particpants, which enables further generalize the results. Therefore, further research comparing interactive behaviors within the FFSF framework of extreme preterm and term infants is recommended to investigate whether the condition of birth specifically interferes with the self-regulatory strategies adopted by infants in stressful situations such as those presented in the still-face episode. We also suggest to investigate the father's role in the infant's self-regulation process and if there are differences when compared to studies with mothers. We conclude by emphasizing the importance of studies on mother-infant interaction and the influence of infant conditions, as in the case of prematurity.

\section{Contributors}

T. CHIODELLI was responsible for the conception, design, data collection, analysis, interpretation of data, discussion of results, revision and approval of the final version of the article. O. M. P. R. RODRIGUES and $V$. A. PEREIRA was responsible for the conception, design, analysis, interpretation of data, discussion of results, revision and approval of the final version of the article. P. LOPES DOS SANTOS and M. FUERTES responsible for the design, interpretation of data, discussion of results, revision and approval of the final version of the article. 


\section{References}

Adamson, L. B., \& Frick, J. E. (2003). The still face: a history of a shared experimental paradigma. Infancy, 4(4), 451-473. http://dx.doi.org/10.1207/S15327078IN0404_01

Agostini, F., Neri, E., Dellabartola, S., Biasini, A., \& Monti, F. (2014). Early interactive behaviours in preterm infants and their mothers: influences of maternal depressive symptomatology and neonatal birth weight. Infant Behavior and Development, 37(1), 86-93. http:/dx.doi.org/10.1016/j.infbeh.2013.12.003

Beebe, B., Myers, M. M., Lee, S. H., Lange, A., Ewing, J., Rubinchik, N., ... Welch, M. G. (2018). Family nurture intervention for preterm infants facilitates positive mother-infant face-to-face engagement at 4 moths. Developmental Psychology, 54(11), 2016-2031. http://dx.doi.org/10.1037/dev0000557

Beeghly, M., Fuertes, M., Liu, C. H., Delonis, M. S., \& Tronick, E. (2011). Maternal sensitivity in dyadic context: mutual regulation, meaning-making, and reparation. In Davis, D. W \& Logsdon, C. (Orgs.), Maternal sensitivity: a scientific foundation for practice (pp.45-69). Hauppauge: Nova Science Publishers.

Beeghly, M., \& Tronick, E. (2011). Early resilience in the context of parent-infant relationships: a social developmental perspective. Current Problems in Pediatric and Adolescent Health Care, 41(7), 197-201. http://dx.doi.org/10.1016/j. cppeds.2011.02.005

Borghini, A., Habersaat, S., Forcada-Guex, M., Nessi, J., Pierrehumbert, B., Ansermet, F., \& Muller-Nix, C. (2014). Effects of an early intervention on maternal post-traumatic stress symptoms and the quality of mother-infant interaction: the case of preterm birth. Infant Behavior and Development, 37(4), 624-631. http://dx.doi.org/10.1016/j.infbeh.2014.08.003

Braungart-Rieker, J. M., Zentall, S., Lickenbrock, D. M., Ekas, N. V., Oshio, T., \& Planalp, E. (2014). Attachment in the making: mother and father sensitivity and infants' responses during the Still-Face Paradigm. Journal of Experimental Child Psychology, 125, 63-84. http://dx.doi.org/10.1016/j.jecp.2014.02.007

Chiodelli, T. (2016). Temperamento e prematuridade: influências sobre a interação mãe-bebê (Dissertação de mestrado não-publicado). Universidade Estadual Paulista Júlio de Mesquita Filho.

Cicchetti, D. V. (1994). Guidelines, criteria, and rules of thumb for evaluating normed and standardized assessment instruments in psychology. Psychological Assessment, 6, 284-290. http://dx.doi.org/10.1037/1040-3590.6.4.284

Dibley, A. L., Rydin-Orwin, T., Stedmon, J., \& Dallos, R. (2016). The feasibility of usind "Premiestart, " a mother-premature infant interaction program, on a Neonatal Unit in England. Infant Mental Health Journal, 37(4), 440-451. http://dx.doi. org/10.1002/imhj. 21572

Field, T. M., Vega-Lahr, N., Scafidi, F., \& Goldstein, S. (1986). Effects of maternal unavailability on mother-infant interactions. Infant Behavior and Development, 9(4), 473-478. http://dx.doi.org/10.1016/0163-6383(86)90019-6

Fuertes, M., Barbosa, M., Faria, A., Lopes dos Santos, P. \& Tronick, E. (2014). The impact of NICU admission and mother-infant interactions on self-comfort behavior of prematurely born infants. Infant Mental Health Journal, 35(5), (Suppl. A), 142-3. Retrieved from https://cdn.ymaws.com/waimh.org/resource/resmgr/images/congresses/2014/waimh_2014_imhj_supplement.pdf

Fuertes, M., Beeghly, M., Lopes dos Santos, P., \& Tronick, E. (2011). Predictors of infant positive, negative and self-direct coping during face to face still-face in a Portuguese preterm sample. Análise Psicológica, 4(29), 553-565. http:// dx.doi.org/ 10.14417/ap.103

Fuertes, M., Lopes dos Santos, P., Beeghly, M., \& Tronick, E. (2009). Infant coping and maternal interactive behavior predict attachment in a Portuguese sample of healthy preterm infants. European Psychologist, 14, 320. http://dx.doi. org/10.1027/1016-9040.14.4.320

Garunkstiene, R., Buinauskiene, J., Uloziene, I., \& Markuniene, E. (2014). Controlled trial of live versus recorded lullabies in preterm infants. Nordic Journal of Music Therapy, 23(1), 71-88. http://dx.doi.org/10.1080/08098131.2013.809783

Gianino, A., \& Tronick, E. Z. (1988). The mutual regulation model: the infant's self and interactive regulation and coping and defensive capacities. In T. Field, P. McCabe, \& N. Schneiderman (Eds.), Stress and coping across development. Hillsdale: Erlbaum.

Gunning, M., Halligan, S. L., \& Murray, L. (2013). Contributions of maternal and infant factors to infant responding to the still face paradigm: a longitudinal study. Infant Behavior and Development, 36(3), 319-328. http://dx.doi. org/10.1016/j.infbeh.2013.02.003

Hsu, H. C., \& Jeng, S. F. (2008). Two-month-olds' attention and affective response to maternal still face: a comparison between term and preterm infants in Taiwan. Infant Behavior and Development, 31(2), 194-206. http://dx.doi.org /10.1016/j.infbeh.2007.10.008

Hsu, H. C., \& Jeng, S. F. (2013). Differential effects of still-face interaction on mothers of term and preterm infants. Infant Mental Health Journal, 34(4), 267-279. http://dx.doi.org/10.1111/j.1467-8624.2009.01296.x 
Jean, A. D. L., \& Stack, D. M. (2012). Full-term and very-low-birth-weight preterm infants' self-regulation behaviors during a still-face interaction: influences of maternal touch. Infant Behavior \& Development, 35(4), 779-791. http:// dx.doi.org/10.1016/j.infbeh.2012.07.023

Loi, E. C., Vaca, K. E. C., Ashland, M. D., Marchman, V. A., Fernald, A., \& Feldman, H. M. (2017). Quality of caregiverchild play interactions with toddlers born preterm and full term: antecedentes and language outcome. Early Human Development, 115, 110-117. http://dx.doi.org/10.1016/j.earlhumdev.2017.10.001

Lowe, J. R., MacLean, P. C., Duncan, A. F., Aragón, C., Schrader, R. M., Caprihan, A., \& Phillips, J. P. (2012). Association of maternal interaction with emotional regulation in 4- and 9-month infants during the Still Face Paradigm. Infant Behavior and Development, 35(2), 295-302. http://dx.doi.org/10.1016/j.infbeh.2011.12.002

Mantis, I., \& Stack, D. M. (2018). The functions of mutual touch in full-term and very low-birthweight/preterm infantmother dyads: associations with infant affect and emotional availability during face-to-face interactions. International Journal of Comparative Psychology, 31(0), 3-24.

Mesman, J., IJzendoorn, M. H., \& Bakermans-Kranenburg, M. J. (2009). The many faces of the still-face paradigm: a review and meta-analysis. Developmental Review, 29(2), 120-162. http://dx.doi.org/10.1016/j.dr.2009.02.001

Montirosso, R., Borgatti, R., Trojan, S., Zanini, R., \& Tronick, E. (2010). A comparison of dyadic interactions and coping with still-face in healthy pre-term and full-term infants. British Journal of Developmental Psychology, 28(2), 347-368. http://dx.doi.org/10.1348/026151009X416429

Montirosso, R., Provenzi, L., Giorda, R., Fumagalli, M., Morandi, F., Sirgiovanni, I., ... Borgatti, R. (2016). SLC6A4 promoter region methylation and socio-emotional stress response in very preterm and full-term infants. Epigenomics, 8(7), 895907. http://dx.doi.org/10.2217/epi-2016-0010

Muller-Nix, C., Forcada-Guex, M., Pierrehumbert, B., Jaunin, L., Borghini, A., \& Ansermet, F. (2004). Prematurity, maternal stress and mother-child interactions. Early Human Development, 79(2), 145-148. http://dx.doi.org/0.1016/j. earlhumdev.2004.05.002

Nayak, B. S., Lewis, L. E., Margaret, B., Bhat, Y. R., D'Almeida, J., \& Phagdol, T. (2019). Randomized controlled trial on effectiveness of mHealth (mobile/smartphone) based Preterm Home Care Program on developmental outcomes of preterms: study protocol. Journal of Advanced Nursing, 75(2), 452-460. http://dx.doi.org/10.1111/jan.13879

Palazzi, A., Meschini, R., \& Piccinini, C. A. (2019). Intervenção musicoterápica para mãe-bebê pré-termo: uma proposta de intervenção na UTI neonatal. Psicologia em Estudo, 24, e41123. http://dx.doi.org/10.4025/psicolestud.v24i0.41123

Pestana, M. H., \& Gageiro, J. N. (2014). Análise de dados para Ciências Sociais: a complementariedade do SPSS. Lisboa: Edições Sílabo.

Ribeiro, C. (2017). A influência da idade gestacional nas habilidades do desenvo/vimento infantil e a qualidade da interação na díade mãe-bebê ao longo do primeiro ano de vida (Tese de doutorado não-publicado). Universidade de São Paulo.

Seixas, I., Barbosa, M., \& Fuertes, M. (2017). Contributos para a autorregulação do bebê no Paradigma Face-to-Face Still-Face. Análise Psicológica, 4(35), 469-485. http://dx.doi.org/ 10.14417/ap.1280

Tronick, E., Als, H., Adamson, L., Wise, S., \& Brazelton, T. B. (1978). The infant's response to entrapment between contradictory messages in face-to-face interaction. American Academy of Child Psychiatry, 17(1), 1-13. http://dx.doi. org/10.1016/S0002-7138(09)62273-1

Varão, A. (2012). Um jogo a dois: interação mãe-bebê e autorregulação infantil (Dissertação de mestrado não-publicado). Instituto Politécnico de Lisboa.

Vonderheid, S. C., Rankin, K., Norr, K., Vasa, R., Hill, S., \& White-Traut, R. (2016). Health case use outcomes of an integrated Hospital-to-Home Mother-Preterm Intervention. Journal of Obstetric, Gynecologic \& Neonatal Nursing, 45(5), 625-638. http://dx.doi.org/10.1016/j.jogn.2016.05.007

Yaari, M., Rotzak, N. L., Mankuta, D., Harel-Gadassi, A., Friedlader, E., Eventoy-Friedman, S., ... Yirmiya, N. (2018). Preterm-infant emotion regulation during the still-face interaction. Infant Behavior and Development, 52, 56-65. http://dx.doi.org/10.1016/j.infbeh. 2018.05.008

Received: January 18, 2019

Final version: October 24, 2019

Approved: November 26, 2019 